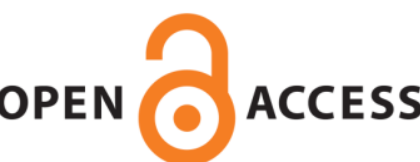

UWS Academic Portal

\title{
The nurse's role in efficiently using telecare
}

Cund, Audrey; Boyd, James

Published in:

Nursing and Residential Care

DOI:

10.12968/nrec.2018.20.10.490

Published: 18/09/2018

Document Version

Peer reviewed version

Link to publication on the UWS Academic Portal

Citation for published version (APA):

Cund, A., \& Boyd, J. (2018). The nurse's role in efficiently using telecare. Nursing and Residential Care, 20(10), 490-496. https://doi.org/10.12968/nrec.2018.20.10.490

\section{General rights}

Copyright and moral rights for the publications made accessible in the UWS Academic Portal are retained by the authors and/or other copyright owners and it is a condition of accessing publications that users recognise and abide by the legal requirements associated with these rights.

\section{Take down policy}

If you believe that this document breaches copyright please contact pure@uws.ac.uk providing details, and we will remove access to the work immediately and investigate your claim. 
"This document is the Accepted Manuscript version of a Published Work that appeared in final form in Nursing and Residential Healthcare, copyright (C) MA Healthcare, after peer review and technical editing by the publisher. To access the final edited and published work see https://doi.org/10.12968/nrec.2018.20.10.490." 
Technological Developments in Care Homes

Authors:

Audrey Cund

Lecturer in Mental Health

University of the West of Scotland

School of Health and Life Sciences

High Street

Paisley

PA1 2BE

Audrey.cund@uws.ac.uk

01418494211

Dr Robert Boyd

Lecturer in Mental health

Lecturer in Mental Health

University of the West of Scotland

School of Health and Life Sciences

High Street

Paisley

PA1 2BE

Robert.boyd@uws.ac.uk 


\begin{abstract}
Telecare and smart home technology are being increasingly used in the community to improve the safety and security of vulnerable groups of people. They are also being used to improve the quality of life of patients by stimulating their minds and physical senses and to enhance communication between patients, health, social care organisations and relatives. Their introduction can also improve efficacy and cut costs. This paper argues that, whilst a lot of care and nursing homes are using these technologies to their advantage, they are possibly not being used to their full potential, especially for direct patient care. Nurses are in the ideal position to implement established technologies and creatively think of new ways to use them in the future.
\end{abstract}

\author{
Keywords \\ Telecare \\ Smart phone technology \\ Nursing homes \\ Long term conditions \\ Ageing
}


Introduction

Telecare and Smart Home Technology is endorsed by multiple Scottish, UK and European documents (Scottish Government 2011, 2015, 2016, Telescope 2014). Key recommendations from these reports has directed the integration of public services and placed an emphasis on using every day technologies to create more choices for citizens thus improving access to, and availability of services (Scottish Government 2015, 2016). This paper examines the range of technology available for use in the care and residential home sector. It also provides some insight into the role of the nurse in terms of supporting the use of telecare and smart technology

\section{Ageing and Technology}

Ageing has long been synonymous with poor health, cognitive decline and frailty ( Amarya, Singh, and Sabharwal, 2018). Age related diseases include cognitive decline, sensory impairment, stroke, cancers arthritis (Hijazi, et al., 2016; Fulop et al. 2010). Depression, loneliness and isolation is also prevalent particularly following the loss of a loved one, pet or significant other (Freeman et al. 2016). This bleak picture is echoed in government documents worldwide and highlight that people are living longer and directly linked to this is the increased prevalence of chronic health conditions (WHO, 2015). At the same time this has placed an increased demand on health, housing and care services to provide the necessary support for people living longer. The use of technology has emerged over the last few decades as a universal approach that can support every person regardless of age, gender, disability and nationality (Pare et al., 2007). This has seen a proliferation of telecare and smart home technology subtlety infiltrate the care sector with innovative technologies such as sensors, robotics and other forms of assistive technologies emerging.

\section{Telecare and Smart Home Technology}

Telecare involves the use of Information and Communication Technology (ICT) devices to provide support, protection and reassurance to the user when they are at a distance from their carer or health and social care provider (Stowe and Harding, 2010). A smart home involves the use of telecare devices and is based on the connection between these devices and a communication network. This allows the devices to be remotely controlled, accessed and monitored (AI-Sumaiti, Ahmed and Salama, 2014). Recent examples of this are Smart Meters where devices within the home can be regulated and controlled from a distance. By creating a novel way to increase home automation this can collate patterns of device use and help to manage energy and environmental emissions. For independent health and care providers this is invaluable information and can help predict patterns and behaviours thus ultimately helping to save time and money. 
Types of Technology

Telecare and Smart Home technology designs and devices are commonly divided into three generations and described as either fixed, mobile or integrated. Fixed designs are built into the property and emphasis is placed on the safety and protection of the individual. Whereas a design that is mobile or portable adds flexibility for the individual and carer. Integrated technology designs use sensors and actuators to automate devices; monitor; and predict health and lifestyle behaviours, e.g. movement and activity levels. Figure 1.1 illustrates how the technology connects in the home.

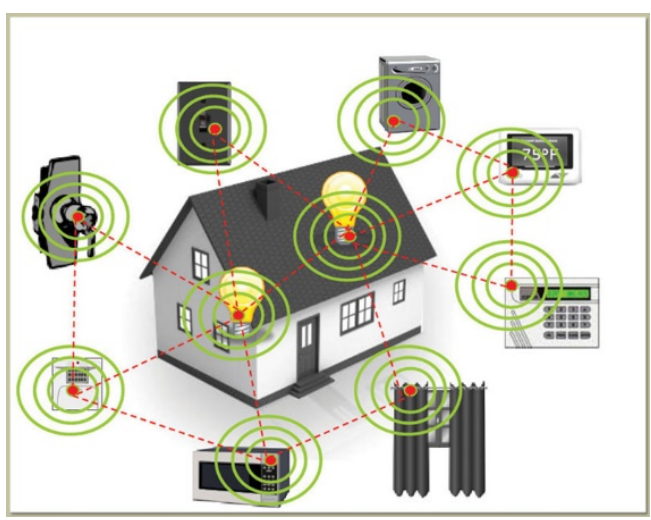

Figure1:Error! No text of specified style in document.:1Example of Smart home connectivity, http://www.ihiji.com/wp-content/uploads/2016/07/ModelHomeNetwork.jpg

\section{First generation}

There is a wide range of equipment available that can help to monitor someone at home. First generation telecare refers to fixed products in the home environment such as fire alarms; carbon monoxide detectors; gas cut off sensors to turn off gas supply if a cooker is left on; flood detectors to report an overflowing sink or bath if a tap is left running; and door contact sensors to monitor the frequency of the door opening and closing. Familiar voice activated devices can also be used to complement the door sensors to remind the person of the time or to remember their keys or lock the door. All these first-generation products serve a primary function of safety and protection as well as provide a sense of security to the individual, families and carers. Fire alarms and other environmental alarms are often forgotten as an important technological innovation as they have now become some of the most widespread devices in use. This type of equipment does not alert a control centre but activates an alarm or signal to the user that action must be taken.

Monitored equipment such as pendant alarms, bed sensors and floor and heat sensors can also be fitted around the home which when activated triggers a response from a call centre. The pendant alarm/ button alarm or pull cord alarm has three interacting components, 1) the button/bracelet/pendant is worn by the user or activated by the user (pull cord); 2) a terminal or base unit is established in the home (linked via a telephone line) with a microphone and speaker as a 
standard feature; and 3) the terminal is linked to a call centre or responder service. Depending on the location of the person the responder may be a neighbour, family member, community support or an official housing/care provider. A new wave of telecare products has recently seen the design, interface and size of the device becoming smaller, colourful and more bespoke to reduce the stigma associated with wearing an alarm, e.g. brooches, bracelets and watches. This has also extended to reducing the size and shape of base units ( ?? ).

\section{$2^{\text {nd }}$ generation}

Second generation telecare devices involve the use of sensors to monitor activities of daily living and provide prompts and or reminders to the user and or carer. Fall detectors are available to automatic alert or signal to a carer that a person has fallen. This is an advancement on the pendant alarm whereby the activation is not required by the user. Epilepsy sensors can be used whilst a person is sleeping to detect movements in bed. The sensor is specially designed to differentiate between normal movements and those of an epileptic seizure. Figure 1.2 shows the range of first and second generation telecare technology.

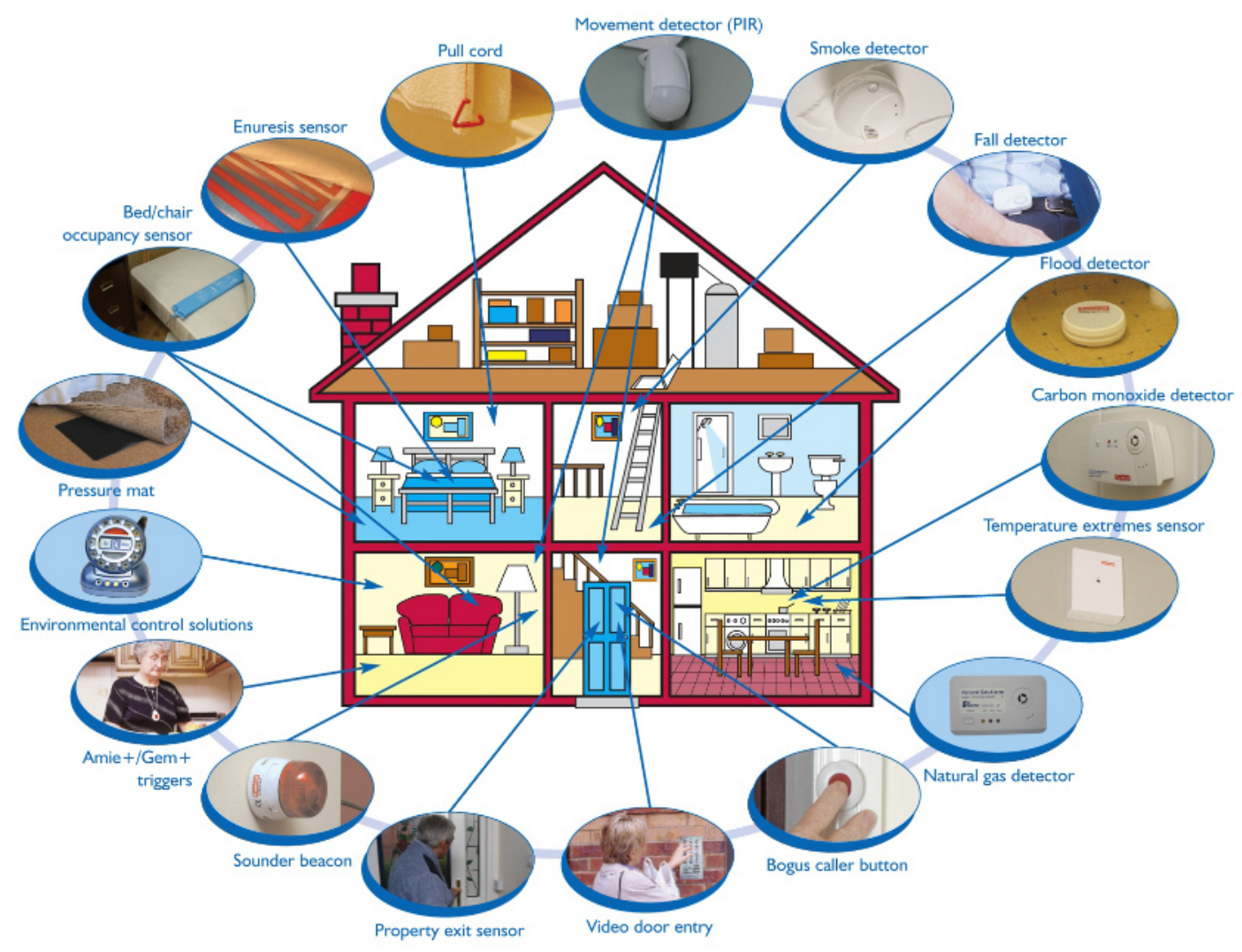

Figure 1:2 example of telecare equipment, image taken from http://www.facilities.ac.uk/i/features/193-telecare-in-the-home 
Third generation

Third generation products involve the use of mobile and portable ICT equipment to gather data on the health and lifestyle of the person, e.g. phone, iPad. This can be used to measure health parameters such as blood pressure, glucose monitoring, oxygen saturations and other physiological measurements. Extensive research has shown that health monitoring at a distance can improve adherence with prescribed treatment, improve quality of life, reduce unplanned hospital admissions and empower people to self-manage (Ware, Seto and Ross, 2018; Buekers et al., 2018; Zwerink et al., 2014).

Sensor technology can also be used around the home to monitor motion activity and alert a carer to no movement. Examples include bed/chair monitors. Data is gathered from Passive Infrared Sensors positioned around the home and this information can be collated remotely via a computer allowing patterns of movement to be analysed, thus enabling care to be adjusted. For example, a relative may identify an increased pattern of activity from the bedroom and living room to the bathroom. This may indicate that the person has bowel or urinary difficulties. For people who are vulnerable and may wander out with the home the use of GPS tracking devices can be used on clothing and worn as an accessory to track and find the person. Smart phones can also be used to perform this function but is reliant on the person remembering to take the phone or charge the battery regularly.

The use of robotics in care and residential is steadily growing with the use of small toy robotic animals providing stimulation and company for people who have advanced dementia and for those who feel isolated and lonely.

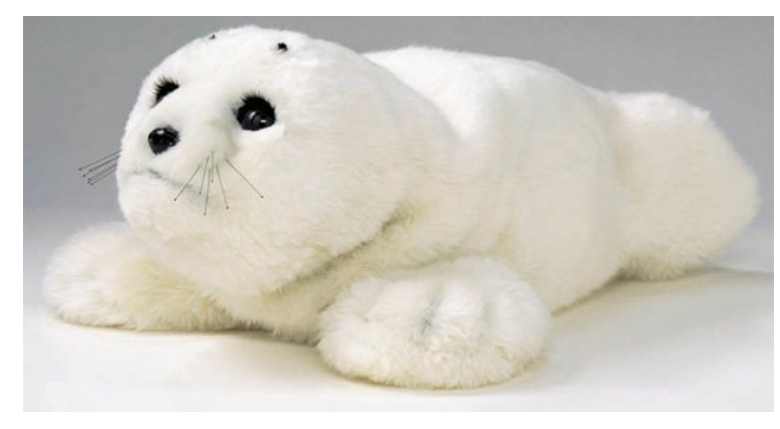

Figure 1:3 PARO Therapeutic Robotic Seal (Image fromhttps://www.japantrendshop.com/paro-robotseal-healing-pet-p-144.html

Recent studies involving patients with advanced dementia have shown that PARO the therapeutic robotic seal (Figure 1.3) has increased the patient's social interaction, engagement and communication with the robot (McGlynn et al., 2017; Robinson et al., 2013). Overall the studies conclude that PARO has had a positive impact on the patient's quality of life. 
So far, the article has explored the types of technology that have evolved over the last few decades. The miniaturisation of devices and the widespread use and adoption of mobile and information communication technologies appears to have extended the possibilities to monitor people more closely. The evidence clearly shows that telecare and smart home technology has a positive impact and the key selling points of the technology are that they offer individuals a sense of safety and security; protection; and peace of mind. Yet despite telecare's widespread use, acceptance and uptake remains low. In the remainder of the article we will explore some of the barriers and facilitators to adopting telecare and smart home technology.

\section{Benefits and Challenges}

Telecare and smart home technology offers significant social and economic benefits particularly for residential and care homes in rural settings (Devlin et al., 2015; Henderson, Knapp and Fermandez, 2013). Extensive research on the use of technology to monitor long term conditions has consistently shown that patients of all ages, genders and nationalities like using technology as it enables them to self-manage, saves them time and reduces the number of visits to doctors and hospitals ( ). The use of surveillance technology has been shown to reduce the need for restraint and subsequently improve the quality of life for people with dementia in nursing homes (Boekhorst; Depla and Francke, 2013). Similarly, infrared sensors that can be directed via text alerts to nursing staffs' mobile devices can reduce falls and allow patients more freedom than they would have otherwise( Vandenberg et al 2017). Indeed, safety and security are often seen as important reasons for introducing technology to nursing homes ( Hoof et al 2016).There has even been a call for 24 hour surveillance to be allow relatives to supervise care given to their loved ones.

The use of Video Conferencing (VC), Skype and or Facetime has also proven to be beneficial as it can connect patients/residents in real time with health professionals and allow teams to consult and review patient/residents progress. This saves time, reduces unnecessary travel thus ensuring more efficient use of resources (AUDIT Scotland 2017). Indeed, one such example is a GP practice in Stafford. The practice has created V-Doc. An iPad which is connected to Skype on a trolley. There is a variety of self-care devices on the trolly, such as, a pulse oximeter. Care home staff move around the nursing homes, similar to a 'ward round', with the V-doc device allowing the GP to carry out consultations from the surgery with remote contact with each patient. Face-to-face consultation are still carried out if anything is deemed more urgent.

Monitoring long term conditions remotely for residents enables GP's and other specialists to consult to observe patterns and respond timely and efficiently enabling changes to be made to an individual's 
care. Monitoring patterns and behaviour such as movement or falls can enable teams to review data and take more proactive steps to reduce risk. Whilst difficult to quantify this has the potential to improve quality of life outcomes, reduce hospital admissions associated with falls and improve standards of care.

A common concern about the use of technology to monitor the person at a distance is that it will replace the need for human contact. This is misleading as the nurse or carer is required to make sense of the data prior to taking action. The idea of monitoring a person's behaviour passively and remotely raises ethical issues around consent, privacy and the security of information. Several authors highlight that advance statements are useful tools to plan ahead in the event of cognitive decline or reduced impairment. Having the conversation about using technology to keep the person safe and monitor patterns and behaviour can help the person staff at home longer.

Kruse et al (2018) highlight that one of the challenges of using telecare and smart home technology is staff acceptance and motivation to use. Several authors highlight that for technology to be used staff need to perceive the technology to be user friendly, better than the existing approach and easy to use (Venkatesh et al., ??book...not et al ). A lack of vision, governance and investment are also commonly expressed in the literature (Bowles, Dykes, and Demiris, 2015). Greenhalgh et al. (2012) agree and caution that for staff to accept the use of technology there needs to be strategic by in and a culture of acceptance is built into the organisations systems and processes. Central to this is the creation of a support networks for staff where new ideas can flourish using the technology. The advancements in technology over recent years and integration of health and care services has raised the need to establish standards and guidelines on the use of telecare and smart home technology. This raises both benefits and challenges in terms of improving consistency across organisations and technology providers however, for established companies this may prove costly in terms meeting/achieving compliance with new regulations or standards.

\section{Nurses role and technology}

Nurses are well placed to support patients to use telecare and smart home technology however, their acceptance of technology has been questioned in the literature for some time. Video technology and video conferencing is cited as one of the most commonly used technology in the care environment and this is used by nurses to consult and provide psycosocial support. virtual nurse clinics are growing in popularity as well as the use of SMS reminders and messages to prompt, remind and collate physiological measurements as well as provide health promotion messages. Regular users of technology have found that it helps facilitate their work; improves accessibility to services for people and enables them to deliver more person-centred care (Lindberg et al., 2013). 
Some of the challenges for nurses relate to their access to ICT in the workplace (The Royal College of Nursing, RCN, 2013 ). Further to this, there is a lack of knowledge and confidence in using ICT to meet the needs of people with long term health conditions. This has resulted in a call to action to improve the digital literacy skills of nurses to ensure they are ready to work in a digital era (RCN, 2017).

\section{Conclusion}

In conclusion, as the population becomes more computer and technologically minded, the needs of ageing population in care homes are changing. Some progressive care home have wifi for their 'silver surfers', and encourage residents to use ipads and mobile devises. By using apps for music, games, health monitoring and even exercise, such as, counting steps, quality of life can be improved. As technology becomes simpler to use, even people with fairly advanced Alzheimer's disease can touch an icon on a tablet to hear their favourite piece of music. Monitoring of residents' health, patient safety and security can all be enhanced by the use of technology in care homes. Communication with professional and relatives can be improved and can complement face to face care delivery. As technology continues to evolve nurses are in the ideal position, not only to implement established smart technology, but to develop and suggest new ways that technology could improve and enhance patient care.

Key points

- Telecare has evolved over three generations and is used to provide safety, protection and peace of mind for users requiring home or residential care monitoring.

- Telecare and smart home technology complements face to face care delivery and helps to save time and resources.

- Nurses are well placed to use telecare and smart home technology to monitor health and patterns of behaviour.

\section{Reflective questions}

- In what way could telecare or smart home technology be introduced to your workplace?

- What addition skills and education do you require to use technology in your workplace?

- Can you write a reflective account (that could count towards revalidation) of a piece of technology that has improved patient care in your area?

- What skills do your patients have that could be utilised to use smart technology to improve their quality of life. 
- How does SMART technology enhance your personal life? 


\section{Reference List}

Amarya, S., Singh, K. and Sabharwal, M., 2018. Ageing Process and Physiological Changes. In Gerontology, IntechOpen.

Ameena, S. Ahmed, M. and Salama, M. A. (2014) Smart Home Activities: A Literature Review, Electric Power Components and Systems, 42:3-4, 294-305, DOI: 10.1080/15325008.2013.832439.

Audit Scotland 2017 Principle for a digital future: lessons learned from public sector ICT projects Boekhorst, S.,Depla, M. F. I. A., Francke, A. L., Twisk, J. W. R., Zwijsen, S. A. and Hertogh, C. M. P. M. 2013 Quality of life of nursing-home residents with dementia subject to surveillance technology versus physical restraints: an explorative study International Journal of Geriatric Psychiatry, April 2013, Vol.28(4), pp.356-363.

Bowles, K.H., Dykes, P. and Demiris, G., 2015. The use of health information technology to improve care and outcomes for older adults. Research in gerontological nursing, 8(1), pp.5-10.

Buekers, J., De Boever, P., Vaes, A. W., Aerts, J. M., Wouters, E. F., Spruit, M. A., and Theunis, J. (2018). Oxygen saturation measurements in telemonitoring of patients with COPD: a systematic review. Expert Review of Respiratory Medicine, Vol 12, Issue 2, 113-123.

Carlisle K. and Warren R. (2013). Qualitative study of home monitoring for the management of type 2 diabetes, Journal of Telemedicine and Telecare, 19 (7) 372-375.

Christensen, K., Doblhammer, G., Rau, R., \& Vaupel, J. W. (2009). Ageing populations: the challenges ahead. The lancet, 374(9696), 1196-1208.

Devlin, A.M., McGee-Lennon, M., O'Donnell, C.A., Bouamrane, M.M., Agbakoba, R., O'Connor, S., Grieve, E., Finch, T., Wyke, S., Watson, N., Browne, S. and Mair, F.S. (2015) Delivering digital health and well-being at scale: lessons learned during the implementation of the DALLAS program in the United Kingdom. Journal of American Medical Informatics Association. Jan;23(1):48-59.

Doughty, K. and Appleby, A. (2016) "Wearable devices to support rehabilitation and social care", Journal of Assistive Technologies, Vol. 10 Issue: 1, pp.51-63.

Freeman, A.T., Santini, Z.I., Tyrovolas, S., Rummel-Kluge, C., Haro, J.M. and Koyanagi, A., 2016. Negative perceptions of ageing predict the onset and persistence of depression and anxiety: Findings 
from a prospective analysis of the Irish Longitudinal Study on Ageing (TILDA). Journal of Affective Disorders, 199, pp.132-138.

Fulop, T., Larbi, A., Witkowski, J.M., McElhaney, J., Loeb, M., Mitnitski, A. and Pawelec, G., 2010. Aging, frailty and age-related diseases. Biogerontology, 11(5), pp.547-563.

Greenhalgh, T., Procter, R., Wherton, J., Sugarhood, P. and Shaw, S. (2012) The organising vision for Telehealth and Telecare: discourse analysis. BMJ Open; 2:e001574. doi:10.1136/bmjopen-2012001574 [Accessed: $12^{\text {th }}$ August 2018]

Henderson, C., Knapp, M., and Femandez, J. L. (2013) Cost effectiveness of Telehealth for patients with long term conditions (Whole Systems Demonstrator Telehealth questionnaire study): nested economic evaluation in a pragmatic, cluster randomized controlled trial. BMJ 346: f1035-f1035.

Hoof, J., Jansenn, M.L., Heesakkers ,C.M.C., Kersbergen, W., Severijns,L.E., Willems,L.A., Marston, H.R., Janssen, B. M. and Nieboer, M.E. (2016) The Importance of Personal Possessions for the Development of a Sense of Home of Nursing Home Residents. Journal of Housing For the Elderly 30:1, pages 35-51.

Hijazi, Z., Lindbäck, J., Alexander, J.H., Hanna, M., Held, C., Hylek, E.M., Lopes, R.D., Oldgren, J., Siegbahn, A., Stewart, R.A. and White, H.D., 2016. The ABC (age, biomarkers, clinical history) stroke risk score: a biomarker-based risk score for predicting stroke in atrial fibrillation. European heart Journal, 37(20), pp.1582-1590.

Krupinski, E. and Bernard, J. (2014) Standards and guidelines in Telemedicine and Telehealth. Healthcare. Vol.2 (1), pp.74-93.

Koch,S. "Healthy ageing supported by technology-a cross-disciplinary research challenge," Informatics for Health and Social Care, vol. 35, no. 3-4, pp. 81-91, 2010.

Koivunen, M. and Saranto, K. (2017). Nursing professionals' experiences of the facilitators and barriers to the use of Telehealth applications: a systematic review of qualitative studies. Scandinavian Journal of Caring Sciences.

Kruse, C. S., Karem, P., Shifflett, K., Vegi, L., Ravi, K. and Brooks, M. (2018). Evaluating barriers to adopting Telemedicine worldwide: A systematic review. Journal of Telemedicine and Telecare, 24(1), 4. 
Lindberg ,B., Nilsson, C., Zotterman, D., Söderberg, S., and Skär, L. Using Information and Communication Technology in Home Care for Communication between Patients, Family Members, and Healthcare Professionals: A Systematic Review," International Journal of Telemedicine and Applications, vol. 2013, Article ID 461829, 31 pages, 2013.

MATCH Home Care Technologies. Mobilising advanced technologies for care at home: developing home care systems to support independent living. Available from: http://www.matchproject.org.uk/main/main.html. \{Accessed: $13^{\text {th }}$ August 2018].

Noel HC, Vogel DC, Erdos JJ, Cornwall D, Levin F. Home telehealth reduces healthcare costs. Telemed J E Health. 2004;10:170-183.

PARO - https://www.japantrendshop.com/paro-robot-seal-healing-pet-p-144.html

Parè $G$, Jaana $M$, Sicotte $C$. Systematic review of home telemonitoring for chronic diseases: the evidence base. J Am Med Inform Assoc. 2007; 14:269-277.

Royal College of Nursing (2013) Positioning Nursing in a digital world: RCN ehealth survey 2012 report, Royal College of Nursing Publication, London.

Royal College of Nursing (2017) Improving digital literacy, Health Education England and Royal College of Nursing publication, London [online] https://www.rcn.org.uk/professionaldevelopment/publications/pub-006129 [Accessed: $16^{\text {th }}$ June 2018].

Stowe, S. and Harding, S. (2010) Telecare, Telehealth and Telemedicine, European Geriatric Medicine, 1: 193-197.

Scottish Government (2012) A national Telehealth and Telecare delivery Plan for Scotland to 2016: Driving Improvement, Integration and Innovation http://www.gov.scot/Publications/2012/12/7791 \{accessed on $18 / 03 / 18\}$.

Scottish Government (2015) ehealth strategy (refreshed) 2014-2017 http://www.gov.scot/Publications/2015/03/5705 (web only) Accessed: $12^{\text {th }}$ August 2018].

Scottish Government (2017) Realising Scotland's full potential in a digital world: a digital strategy for Scotland https://beta.gov.scot/publications/realising-scotlands-full-potential-digital-world-digitalstrategy-scotland/ (web only), [Accessed:13 ${ }^{\text {th }}$ August 2018]. 
Scottish Government (2018) Technology and Innovation in health and social care https://digitalpublications.parliament.scot/Committees/Report/HS/2018/2/1/Technology-andinnovation-in-health-and-social-care\#Introduction (web only) [Accessed: $13^{\text {th }}$ August 2018].

Van Dyk, L. (2014). A review of Telehealth service implementation Frameworks. International Journal of Environmental Research and Public Health, 11(2), pp.1279-1298.

Vandenberg, A.,Van Beijnum, B. , Overdevest, V. G. , Capezuti, E. ; Johnson,T.M.. US and Dutch, U.S 2017 nurse experiences with fall prevention technology within nursing home environment and workflow: A qualitative study. Geriatric Nursing, July-August 2017, Vol.38(4), pp.276-282.

Vilstrup, D. L., Madsen, E. E., Hansen, C. F. and Wind, G. (2017). Nurses' Use of iPads in Home CareWhat Does It Mean to Patients? A Qualitative Study. Computers, Informatics, Nursing, 35(3), 140.

Ware, P., Seto, E. and Ross, H. J. (2018). Accounting for Complexity in Home Telemonitoring: A Need for Context-Centred Evidence. Canadian Journal of Cardiology [online] https://www.sciencedirect.com/science/article/pii/S0828282X18300400 [Accessed: $21^{\text {st }}$ April 2018].

World Health Organisation (WHO) 2015 World report on ageing and health. \{Online\} available: http://www.who.int/ageing/events/world-report-2015-launch/en/\{Accessed: $13^{\text {th }}$ August 2018].

World Health Organisation (2016) Global diffusion of ehealth,

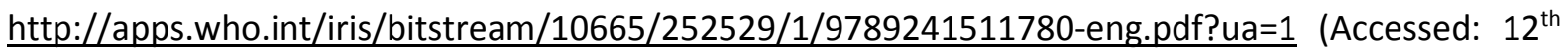
August 2018)

Zwerink, M., Brusse-Keizer, M., van der Valk, P. D., Zielhuis, G. A., Monninkhof, E. M., van der Palen, J., .\& Effing, T. (2014). Self-management for patients with chronic obstructive pulmonary disease. The Cochrane Library. 